\title{
Phenomena and characteristics of barrier river reaches in the middle and lower Yangtze River, China
}

\author{
Xingying You ${ }^{1,2, *}$ and Jinwu TANG ${ }^{3}$ \\ ${ }^{1}$ State Key Laboratory of Water Resource and Hydropower Engineering Science, Wuhan University, \\ Wuhan, China. \\ ${ }^{2}$ Hubei Provincial Water Resources and Hydropower Planning Survey and Design Institute, \\ Wuhan, China. \\ ${ }^{3}$ Changjiang Institute of Survey Planning Design and Research, Wuhan, China. \\ *Corresponding author. e-mail: you_tang@foxmail.com
}

MS received 29 August 2016; revised 24 January 2017; accepted 2 February 2017; published online 20 June 2017

Alluvial river self-adjustment describes the mechanism whereby a river that was originally in an equilibrium state of sediment transport encounters some disturbance that destroys the balance and results in responses such as riverbed deformation. A systematic study of historical and recent aerial photographs and topographic maps in the Middle and Lower Reaches of the Yangtze River (MLYR) shows that river self-adjustment has the distinguishing feature of transferring from upstream to downstream, which may affect flood safety, waterway morphology, bank stability, and aquatic environmental safety over relatively long reaches downstream. As a result, it is necessary to take measures to control or block this transfer. Using the relationship of the occurrence time of channel adjustments between the upstream and downstream, 34 single-thread river reaches in the MLYR were classified into four types: corresponding, basically corresponding, basically not corresponding, not corresponding. The latter two types, because of their ability to prevent upstream channel adjustment from transferring downstream, are called barrier river reaches in this study. Statistics indicate that barrier river reaches are generally single thread and slightly curved, with a narrow and deep cross-sectional morphology, and without flow deflecting nodes in the upper and middle parts of reaches. Moreover, in the MLYR, barrier river reaches have a hydrogeometric coefficient of $<4$, a gradient $>1.2 \%$, a silty clay content of the concave bank $>9.5 \%$, and a median diameter of the bed sediment $>0.158 \mathrm{~mm}$. The barrier river reach mechanism lies in that can effectively centralise the planimetric position of the main stream from different upstream directions, meaning that no matter how the upper channel adjusts, the main stream shows little change, providing relatively stable inflow conditions for the lower reaches. Regarding river regulation, it is necessary to optimise the benefits of barrier river reaches; long river reaches without barrier properties should be systematically planned and regulated; drastic bank collapse and sandbar shrinking should be urgently controlled to prevent the loss of barrier effects.

Keywords. Barrier river reaches; channel adjustment; downstream transfer; main stream migration; Yangtze River.

Supplementary material pertaining to this article is available on the Journal of Earth System Science website (http://www. ias.ac.in/Journals/Journal_of_Earth_System_Science). 


\section{Introduction}

Alluvial rivers are characterised by water and sediment transport channels that undergo constant change. River self-adjustment describes a fluvial process of riverbed deformation in response to sediment transport equilibrium failure caused by an artificial disturbance (Ramos and Gracia 2012). The reasons for river regime adjustment include both artificial and natural stimuli. Artificial stimuli mainly include road or bridge construction (Armaş et al. 2012), dam building, sand mining (Henshaw et al. 2013), dredging, and canalisation (Hajdukiewicz et al. 2016). Natural stimuli include storm flooding and riparian vegetation change (Ramos and Gracia 2012), channel avulsion (Cserkész-Nagy et al. 2010; Kiss et al. 2011), bedrock uplift caused by tectonic movement (Roy and Sahu 2015), river diversion caused by volcaniclastic sediments (Umazano et al. 2014), etc. Implementation of measures to stabilise the river regime has always been the focus of river regulation and management (Greenwood et al. 2016).

An in-depth understanding of channel adjustment forms the basis for achieving the desired river regulation results (David et al. 2016). Recently, due to the influence of human activities like dam building, sand mining, and canalisation, many rivers in Europe and North America have shown an evolution towards narrowing, downcutting, tributary blocking, and main branch strengthening (Surian and Rinaldi 2003; Korpak 2007; Hudson et al. 2008; Armaş et al. 2012). By recognising the reasons for channel adjustment, scientists have proposed targeted remediation methods, implemented worldwide river restoration measures (Huang and Dong 1999; Duan et al. 2009; Remo et al. 2009; Chen and Ho 2013; Doulatyari et al. 2014; Karambas and Samaras 2014; Williams et al. 2014; Hajdukiewicz et al. 2016), and accumulated valuable experience in maintaining river stability and restoring the aquatic ecological environment.

River channels differ in their abilities to cope with artificial stimuli. Downs and Gregory (1993) described geomorphic river sensitivity as a measure of how sensitively a channel responds to artificial disturbances. Brierley and Fryirs (2005) proposed that sensitive reaches were subject to high rates of adjustment in response to stimuli; in contrast, resilient reaches inhibited change by absorbing excess energy and minimising the extent of adjustment in response to stimuli. Reid and Brierley (2015) divided reaches into low, medium, and higher sensitivities by evaluating 'freedom space to move' or 'capacity for adjustment'. In fact, connectivity within landscape compartments could affect the operation of sediment cascades and determine how geomorphic instability deals with artificial disturbances. The connectivity shapes the direction and rate of geomorphic change, with lagging or propagating responses (Goodbred and Kuehl 1998; Sidorchuk 2003). Fryirs et al. (2007) introduced the concept of landform impediments termed buffers, barriers, and blankets, which impede sediment transport by destroying connectivity. Therefore, barriers inhibit sediment movement along channels and disrupt longitudinal linkages. These studies enrich our theoretical knowledge of how river channels adjust in order to cope with artificial stimuli.

However, whether there is blocking phenomena in the propagation process of the natural stimuli inside the river remains unknown. Previous fluvial geomorphology studies have found that upstream channel adjustment tends to transfer downstream (Ramos and Gracia 2012), and could lead to downstream riverbed deformation, such as the main stream migration, translocation of the main and secondary branches, scouring and silting of the point bar and central bar, and substantial riparian collapse (Jun et al. 2012; Zhang et al. 2015; Reid and Brierley 2015; Mossa 2016). In other words, the downstream river regime always corresponds to the specially appointed upstream river regime, thus the river interior adjustment will trigger a chain reaction over quite a long river reaches downstream. As mentioned above, Fryirs et al. (2007) differentiated the sensitivity of different river patterns in dealing with an artificial disturbance, and proposed several different landform impediments that obstruct geomorphic connectivity. In this sense, there may also be river processes capable of dealing with natural interferences. These could lessen or prevent channel adjustment from propagating downstream by way of limiting the planimetric migration of the main stream, just as landform impediments attenuate sediment cascades, thereby preventing the upstream natural interference from triggering the downstream profound and lasting channel adjustment.

For example, the upper reach of the Quelite River in Mexico was a single-thread meandering river in 1986, whose thalweg experienced a chute cutoff during 1986-2003, whereby the curvature gradually decreased and the reach became a braided river accompanied by main channel avulsion in 2007. However, the lower reach flowed 
through the old river and formed a braided river in 1996-1999, before becoming a single-thread river in 2003 (Ramos and Gracia 2012). Another example is the Ahr River in Italy. The Mühlen reach in the upstream achieved its maximum river width in 1950, was still multi-thread in 1970, then narrowed to a single-thread river in 1980. Conversely, the Gais reach downstream was a single-thread river in 1940, whose width increased continuously in the 1970s until achieving its maximum by 2011 (Campana et al. 2014). Evidently, the time of occurrence of the channel adjustment between the upstream and downstream was not synchronous in the above examples; maybe the middle reaches played roles of blocking the river regime adjustment propagation. Ordinarily, a multi-thread channel is more sensitive than a single-thread channel. This means that the former is less likely to avoid river regime transfer, but the latter can remain stable because of its single-thread and microbending morphology, with less lateral migration of the main channel due to a narrow and deep cross-section and low channel mobility (David et al. 2016). However, none of these studies proposed the concept of a barrier river reach.

In this study, based on an in-depth understanding of river evolution features and the regularity of channel adjustment in the Middle and Lower Reaches of the Yangtze River (MLYR), the relationships between the occurrence time of upstream and downstream river regime adjustment were established, and the barrier properties of the singlethread reaches in the MLYR were classified accordingly. Twelve river reaches were defined as 'barrier river reaches', which prevent river regime adjustment in the upper reaches from transferring to the lower reaches. The planar, cross-sectional, longitudinal, and geological characteristics of barrier river reaches were also studied and their application in river regime regulation was explored. These findings may serve as a reference for the river restoration and management in the future.

According to recent aerial photographs and topographic maps, the planar morphologies, the curvature radius of the bend, and the node distribution can be analysed. The hydrogeometric coefficient under different flow levels can be calculated on the basis of the typical cross-sectional topography data that is extracted from the Digital Elevation Model of the National Aeronautics and Space Administration (NASA). The channel longitudinal gradient, the difference of thalweg elevation between inlet and outlet which is divided by the river segment length, not only reflects the magnitude of the flow potential energy, but also intuitively reflects the channel longitudinal profile, determines and replaces the water surface longitudinal gradient. According to the geotechnical investigation data of the riverbank in the MLYR accumulated by the Hubei Provincial Water Resources Hydropower Planning Survey and Design Institute, the material composition and physical performance of the concave bank can be summarised within a depth range of $30 \mathrm{~m}$ from the top of the river bank. The percentage of silty clay content accounting for the total bank is calculated by obtaining the average of the silty clay content for each soil layer weighted by its thickness. The median diameter of bed sediment is provided by the Hydrology Bureau of Changjiang Water Resources Commission (figure 6).

\section{Study area}

Yangtze River is the longest river in China, with a total length of more than $6300 \mathrm{~km}$. The reach from Yichang to the estuary is considered as the MLYR, with a length of $1893 \mathrm{~km}$. Among them, YichangDatong is a runoff reach and the downstream reach from Datong is a tidal reach. Zhicheng-Chenglingji is generally called the Jingjiang River, which is distinguished into the upper and lower Jingjiang River by the dividing point of Ouchikou. There are three distributary openings, Songzikou, Taipingkou, and Ouchikou at the south bank of the Jingjiang Reach, diverting water from the trunk stream to the Dongting Lake, where the water body rejoins the Yangtze River at Chenglingji. There are primary tributaries such as Hanjiang River, which joins at Wuhan Reach, and Poyang Lake, which joins at Jiujiang Reach (Fang et al. 2012; Lai et al. 2014). The main river patterns in the MLYR include single-thread straight rivers, singlethread meandering rivers, and braided rivers (Chen et al. 2012; Song et al. 2016). Channel adjustments come in many forms (Bawa et al. 2014): chute cutoff, large-scale riparian collapse, translocation of the main and secondary branches, and curve cutoff, whose common characteristic is the substantial planimetric migration of the thalweg, accompanied by erosion and deposition of the point bar and central bar.

River regime adjustment in the MLYR is characterised by transferring from upstream to downstream, which is also one of the main influencing 
factors on riverbed evolution. The Jingjiang Reach is famous for 'If one bend changes, every bend changes' (Chen et al. 2012). Because the transfer effect in the MLYR usually lasts for years or even decades and often involves multiple reaches, it is both temporally and spatially large-scale. As the sandy riverbed has high mobility and is easily affected by upstream river regime changes (Wang et al. 2007; Dai and Liu 2013), we use 34 single-thread reaches with sandy riverbeds from Shashi to Datong as study areas (figure 1). Aerial photographs come from Landsat satellite digital products that are available for free from the US Geological Survey (USGS).

\section{The barrier reach phenomenon}

Systematic analysis of the large-scale temporal and spatial evolution of the MLYR shows that, in places where barrier river reaches are present, the upstream channel adjustments may not propagate to downstream. The Tiaoguan Reach, the Tashiyi Reach, the Longkou Reach, and the Huangshi Reach are taken as examples to illustrate this phenomenon.

As shown in figure 2, the Longkou Reach connects upstream with the Luxikou Reach, and downstream with the Jiayu Reach, which are both braided rivers. Based on figure 2, the interannual periodic evolution regularity of Luxikou Reach can be described as follows: low shoals at the head of middle sandbar were cut and a new middle channel was generated $\rightarrow$ new middle channel developed and moved downstream $\rightarrow$ new middle channel combined with old channels $\rightarrow$ middle channel continued bending and moved downstream $\rightarrow$ new middle channel regenerated and developed. There have been five evolution cycles since the 1930s: 1935-1957; 1958-1970; 1971-1982; 1983-2005; and 2006-present. At the beginning of a cycle, the main stream line located at the new middle channel, like 1958, 1973, 1984, 2006; but in the later period of a cycle, the main stream line located at the circle channel or old middle channel, like 1935, 1967, 1982, 2000. Jiayu Reach also displayed interannual periodic evolution. In each cycle, the Wangjiazhou point bar was deposited and eroded, before moving downstream and ultimately joining with the Huxianzhou, and the left branch transformed from a single-groove to a double-groove and then to a single-groove again. Since the early 1920s, Jiayu Reach has experienced two evolution cycles:
1933-1980 and 1981-present. The main stream was located in the east channel in 1984, in the double channel in 1995, and in the middle channel in 2006. Comparison of the interannual evolution of Jiayu Reach and Luxikou Reach shows that, even though both evolutions were periodic, they had different numbers of cycles. Luxikou Reach experienced five evolution cycles since the 1930s, while Jiayu Reach experienced only two. Longkou Reach prevented the transfer of channel adjustment from Luxikou Reach to Jiayu Reach. Moreover, according to figure 2, the downstream river regime of Longkou Reach remained unchanged regardless of the evolution cycle stage of Luxikou Reach. This meant that the adjustment of Luxikou Reach was not transferred downstream and that Longkou Reach assumed the role of a barrier.

As shown in figure 3, the Hekou Reach is connected downstream to, in order, Tiaoguan Reach, Laijiapu Reach, Tashiyi Reach and Jianli Reach. Hekou Reach and Laijiapu Reach formed by the natural cut-off of Shatanzi in 1972 and the artificial cut-off of Zhongzhouzi in 1967, respectively. After the Shatanzi cut-off, the channel downstream from the outlet of the diversion canal evolved from west-convex to east-convex, with a long river bank collapse upstream from Tiaoguan; yet this phenomenon did not cause channel deformation downstream from Tiaoguan. Furthermore, after the Zhongzhouzi cut-off, the riverbank downstream from the diversion canal outlet rapidly retreated $1.5 \mathrm{~km}$, with the channel migration too, but Tashiyi Reach downstream showed no significant deformation. Jianli Reach which is a braided river displayed the following interannual periodic evolution regularity: the direct branch formed and developed $\rightarrow$ the thalweg moved left, and the flow path meandered and lengthened $\rightarrow$ the direct branch deteriorated $\rightarrow$ the direct branch regenerated". Since the 1930s, the river has experienced three evolution cycles: 1931-1970, 1971-1989, and 1989present, mainly influenced by the fact that the head of Wuguizhou was prone to be cut, and the concave bank was prone to collapse ( $\mathrm{Li}$ et al. 2007). In the later period of a cycle, such as 1965 and 1981, the main stream line located at the circle channel. As long as the channel perimeter conditions remained unchanged, the cyclical translocation between the main and secondary channel continued. The evolution cycle of Jianli Reach was not synchronised to the time of the Zhongzhouzi cut-off, owing to the blocking effect of Tashiyi Reach. Moreover, the two cut-offs occurred only in the 1960s-1970s, during 

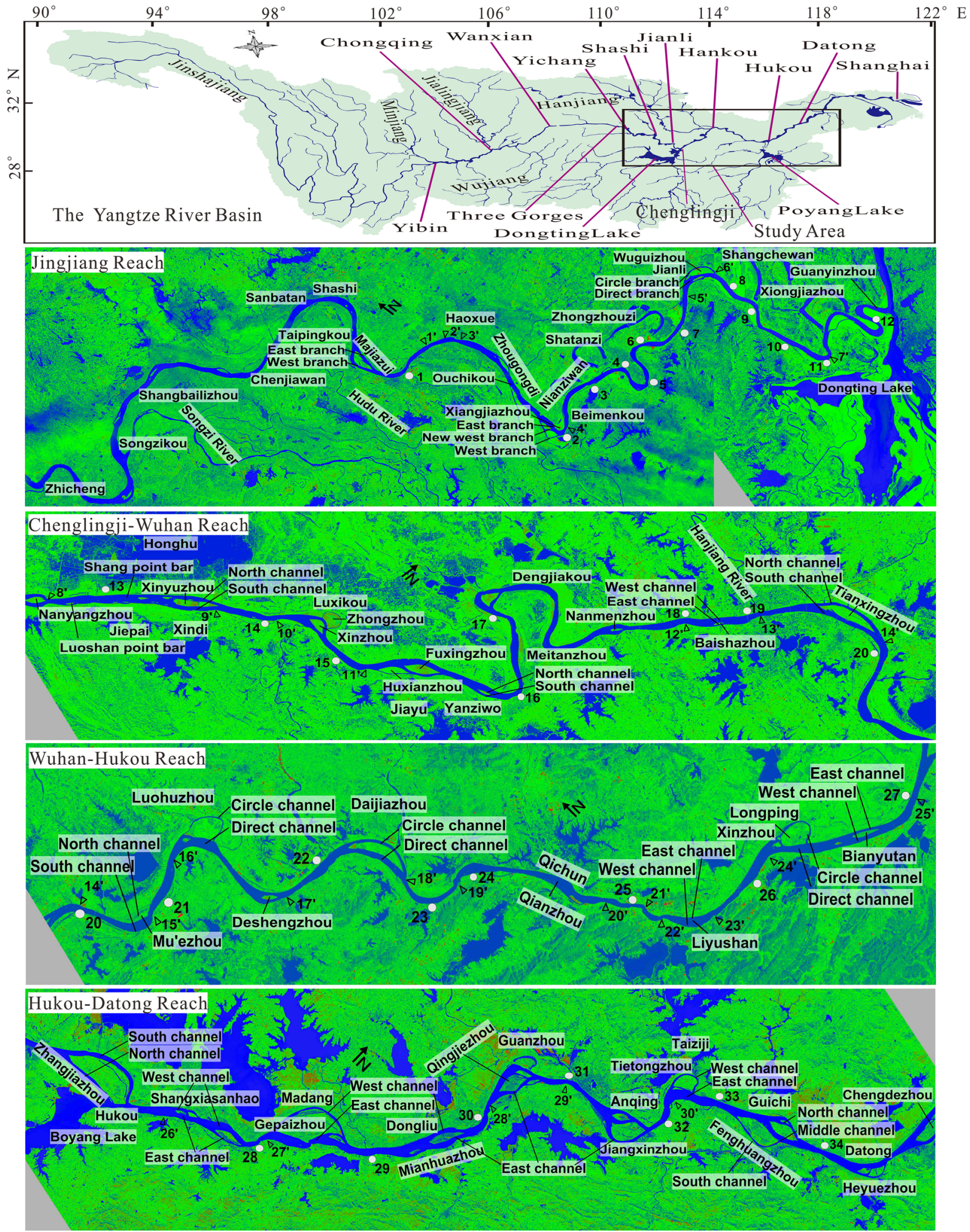

1-Douhudi, 2-Shishou, 3-Nianziwan, 4-Hekou, 5-Tiaoguan, 6-Laijiapu, 7-Tashiyi, 8-Damazhou, 9-Zhuanqiao, 10-Tiepu, 11-Fanzui, 12-Qigongling, 13-Luoshan, 14-Shitouguan, 15-Longkou, 16-Hanjinguan, 17-Paizhouwan, 18-Zhuankou, 19-Wuqiao, 20-Yangluo, 21-Huguang, 22-Bahe, 23-Huangshi, 24-Guniusha, 25-Gepaiji, 26-Wuxue, 27-Jiujiang, 28-Shangxiasanhao-Madang, 29-Madang-Dongliu, 30-Dongliu-Guanzhou, 31-Guanzhou-Anqing, 32-Anqing-Taiziji, 33-Taiziji-Guichi, 34-Datong. 1'-30' are the names of the nodes in this figure: 1'-Chongheguan, 2'-Lingguanji, 3'-Tieniuji, 4'-Dongyueshan, 5'-Xishan, 6'-Taiheji, 7'-Jingjiangmen, 8'-Yanglinshan, 9'-Huanggaishan, 10'-Chibishan, 11'-Shijitou, 12'-Yangsiji, 13'-Shenshan, 14'-Yangluoji, 15'-Baihushan, 16'-Niji, 17'-Guanyinge, 18'-Huifengji, 19'-Xisaishan, 20'-Hou'erji, 21'-Niuguanji, 22'-Banbishan, 23'-Goutouji, 24'-Sanweishan, 25'-Suojianglou, 26'-Baogongshan, 27'-Penglangji, 28'-Jiyangji, 29'-Xiaozhakou, 30'-Lanjiangji.

Figure 1. Sketch map of the Shashi-Datong Reach in the MLYR of China. 


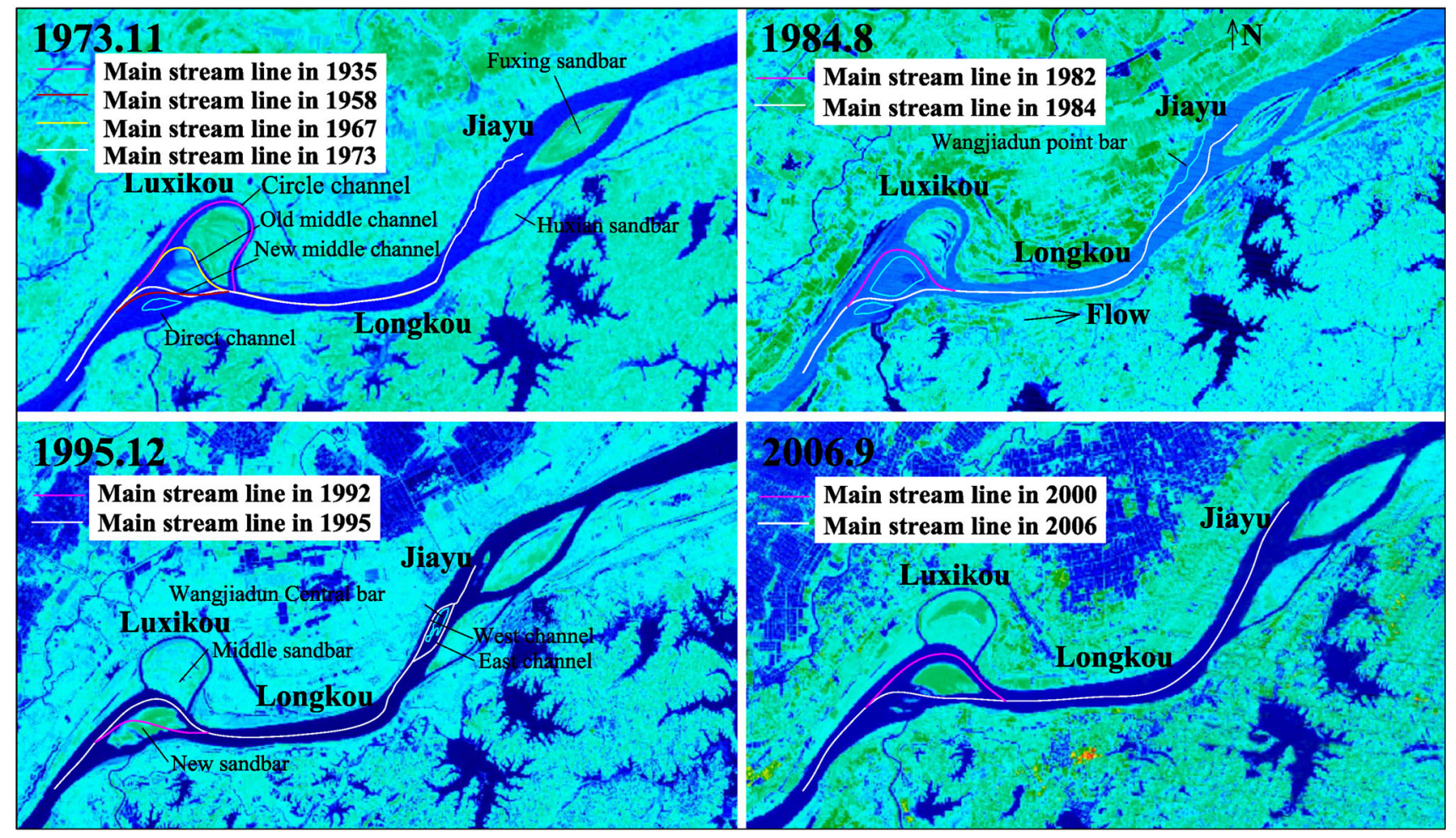

Figure 2. Channel adjustment of Luxikou-Jiayu Reach.
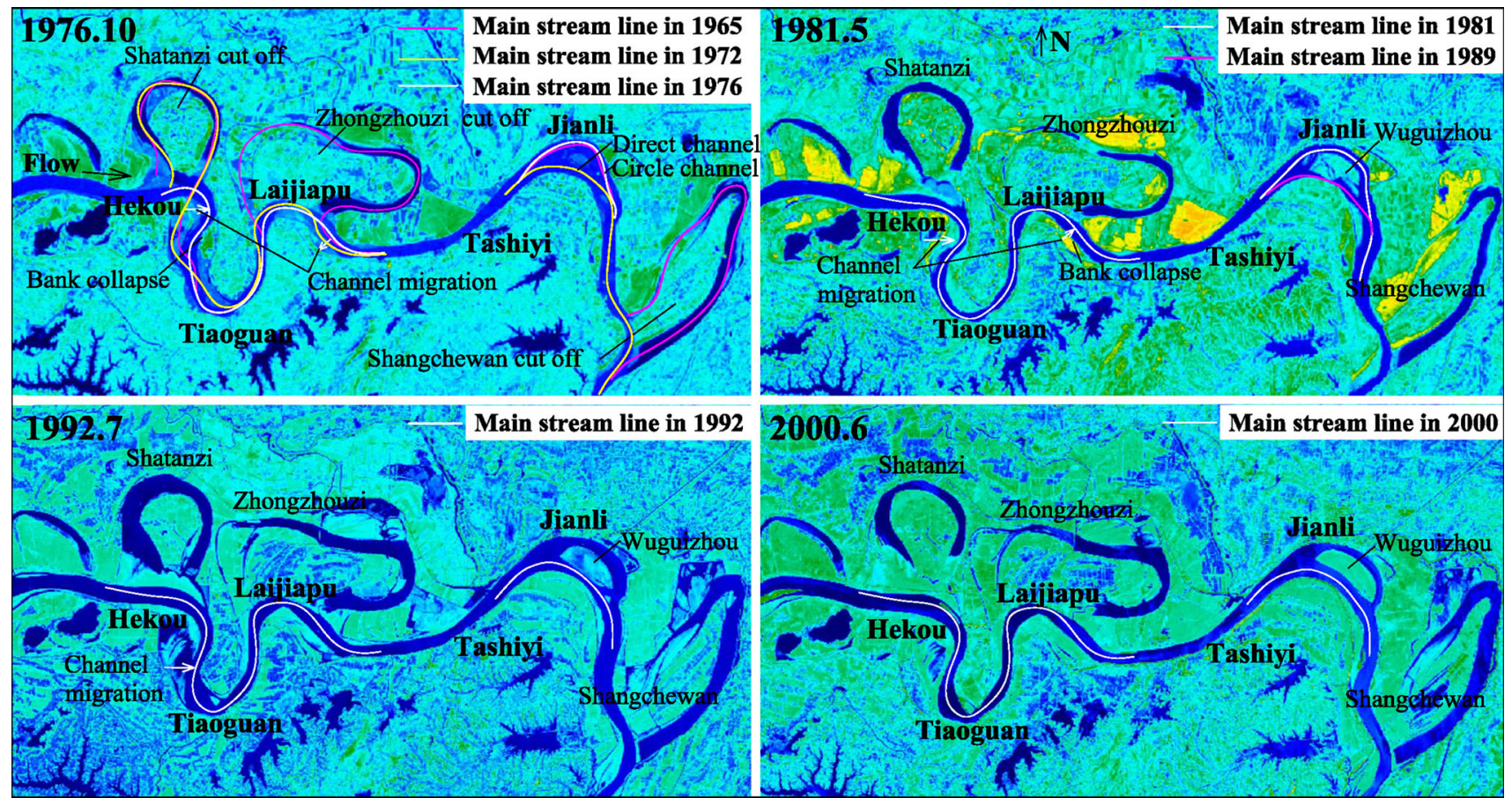

Figure 3. Channel adjustment of Hekou-Jianli Reach.

which time the riverbed morphologies of Tiaoguan Reach and Tashiyi Reach remained stable, indicating that the channel adjustment caused by the cut-off did not affect the lower reaches because
Tiaoguan Reach and Tashiyi Reach had a barrier effect.

As shown in figure 4, the Huangshi Reach connects upstream with the Daijiazhou Reach, which is 

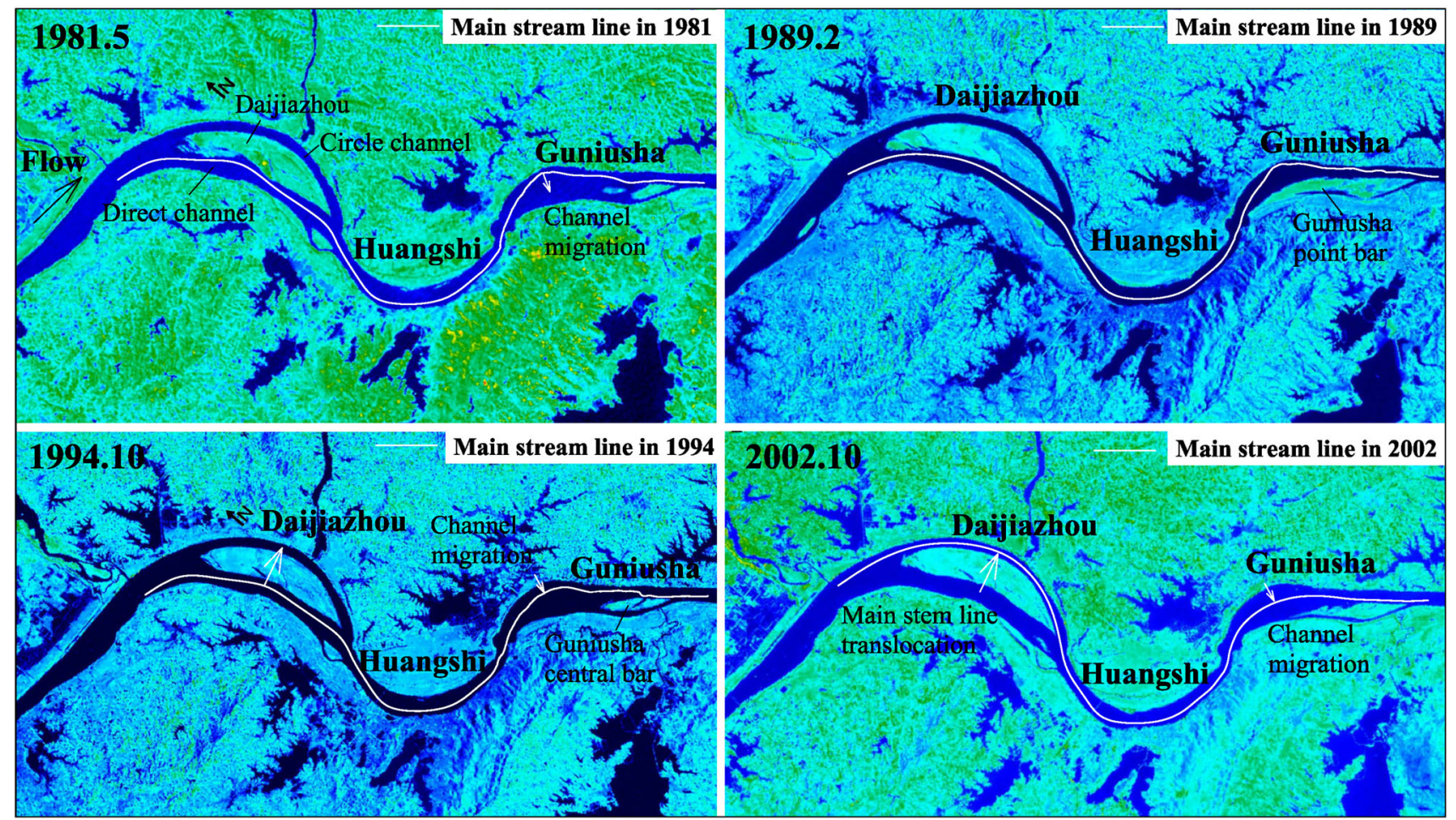

Figure 4. Channel adjustment of Daijiazhou-Guniusha Reach.

a braided river, and downstream with the Guniusha Reach. Daijiazhou Reach showed a tendency for alternating translocation between the circular and direct branches: the circle and direct channels were at a stalemate in 1958-1965; the direct channel was the main branch in 1966-2001; and the two channels were at a stalemate again in 2002-present. Over the same period, the main stream line of Huangshi Reach consistently inclined to the right bank, encountering the deflecting flow of the Xisaishan node, and then inclined to the left bank of Guniusha Reach. With the Guniusha point bar constantly scouring and retreating, even being cut into a central bar, the main stream line of Guniusha Reach was gradually displaced from the left bank to the rivercentre. Comparison of the evolution of Daijiazhou Reach and Guniusha Reach showed that the main stream of Daijiazhou Reach experienced alternating translocation whereas Guniusha Reach continuously migrated to the west. The occurrence time of evolution of upstream and downstream reaches was not synchronous, indicating that Huangshi Reach in the midstream, with a long-term stable channel, prevented the channel adjustment of Daijiazhou Reach from transferring downstream, exerting a barrier effect.

There are many similar phenomena in the MLYR as the above examples. After the upstream river regime adjusts, the downstream reach may weaken or eliminate the upstream influence, may also magnify the upstream influence. In order to make clear what the downstream reach would do, the corresponding relationship between the upstream and downstream river regime adjustment should be systemically summarized. If the upstream and downstream river regime adjustment corresponds very well, their channel adjustment occurrence time are synchronous, the numbers of the adjustment cycles, even the adjustment forms are all the same, then the midstream river reach obviously has no barrier properties. On the contrary, the river reach may have barrier properties. Thus this research analyzes the relationship of upstream and downstream channel adjustment phenomena from the above three aspects, as shown in supplementary table S1. According to table S1, the corresponding degree between the upstream and downstream adjustments of 34 single-thread reaches in the MLYR can be divided into four types: corresponding, basically corresponding, basically not corresponding, not corresponding, where, 'basically not corresponding' and 'not corresponding' reaches are listed as barrier river reaches, shown as in figure 5. And the above four categories separately accounted for $29.63 \%, 37.04 \%, 11.11 \%$ and $22.22 \%$. 


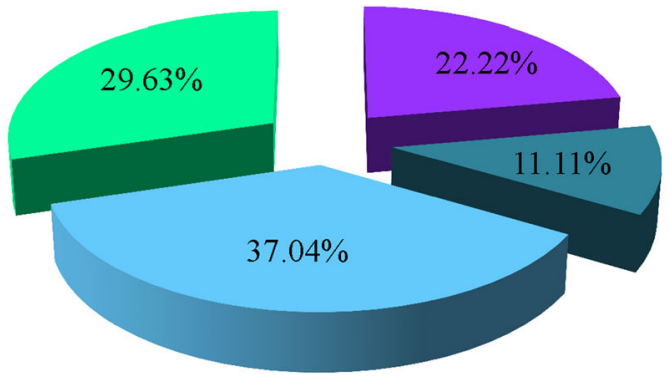

Not corresponding Basically corresponding

Basically not corresponding Corresponding

Figure 5. Classification of the barrier feature.

\section{Characteristics}

\subsection{Planar and cross-sectional characteristics}

The single thread straight river, because of its wider cross-section and weaker circulation effect, is difficult to constrain the change of the inflow direction caused by the upstream channel adjustment, with the periodic evolution of staggered point bars, causing the main stream line (hydrodynamic axis line, means the connection line of maximum vertical averaged flow velocity) to migrate drastically. The channel having greater river width, frequently with broad flood plain, provides plenty migration room for the hydrodynamic axis line, when the water flows over the flood plain and the hydrogeometric coefficient (usually expressed as $\varsigma=\sqrt{ } B / h$ ) suddenly increases. At this same time, if upstream channel adjusts, it is bound to cause the migration of the hydrodynamic axis and the downstream transfer of the channel adjustment.

Further research shows that, the exposed bedrock with strong anti-scourability protruding from the bank, similar to a spur dike and hereafter called a node, has a flow deflection effect, and clearly differs from the smooth bedrock that can restrict hydrodynamic axis migration (Bravard 2010; Bawa et al. 2014). The node decreases the river width, increasing the local flow velocity and leading to different scales of water vortexes, and promoting the formation of a local scour hole (Euler and Herget 2012). When the node is distributed in upper or middle part of the river reach, the continuities of the planar and cross-sectional morphologies of the channel are destroyed abruptly, causing the sudden migration of the hydrodynamic axis line. Especially after the upstream channel adjusts, the inflow angle changes, and the proximity degree of the hydrodynamic axis with the node also varies, the intensity of the node deflecting flow changes, resulting in that the direction of the outflow hydrodynamic axis changes greatly (figure 7).

Therefore, a barrier reach, compared to a straight, wide, and shallow non-barrier reach, usually has a smaller curvature radius of the curve and a smaller hydrogeometric coefficient, and has no node in the upper and middle reach, helping to prevent the hydrodynamic axis from migrating, thereby promoting the formation of a barrier reach. The planar and cross-sectional features of each single-thread reach in the MLYR are as follows:

In the 12 single-thread reaches of the Jingjiang River, which is famous for a winding and tortuous river course, Reach 10 is the only straight reach with a large $R_{*}$, and therefore is not able to constrain movement of the hydrodynamic axis and has no barrier properties. In the remaining 11 reaches with slightly bent planar morphologies, $\zeta$ values of Reaches 1, 2, 4, 5, 6, 7, 9, 11, and 12 , whose cross-sectional configurations are narrow and deep, are all $<4$ and are therefore capable of restricting hydrodynamic axis migration. But $\zeta$ values of Reaches 3 and 8 , whose wide and shallow cross-sectional configurations allow more migrations of the hydrodynamic axes, are $>4$. On the planar-view of the Jingjiang River, Node 4 is located in the middle of the right bank of Reach 2 , which may change the flow direction and cause frequent movement of the hydrodynamic axis, having no barrier properties. Conversely, Node 1 and Node 5 are located at the outlets of Reach 1 and Reach 7, respectively, favouring convergence rather than divergence of the upstream flow, due to both having barrier properties.

In the seven single-thread reaches of the Chenglingji-Hankou River, Reaches 13, 18, and 19 are straight reaches with larger $R_{*}$, therefore lack of barrier properties means it is difficult for them to maintain stable hydrodynamic axes. In the remaining four reaches with slightly bent planar morphologies, $\zeta$ values of Reaches 15, 16, and 17, whose cross-sectional configurations are narrow and deep and beneficial for constraining hydrodynamic axes migrate are all $<4$. But the $\zeta$ value of Reach 14, whose wide and shallow cross-section indicates a lack of barrier properties is $>4$. Meanwhile, Node 9, Node 12, and Node 13 are located in the upper or middle part of Reach 14, Reach 18, and Reach 19, respectively, meaning that hydrodynamic axis is prone to migrate. Conversely, Node 11, located at the outlet of Reach 15, would not lead to migration of the 

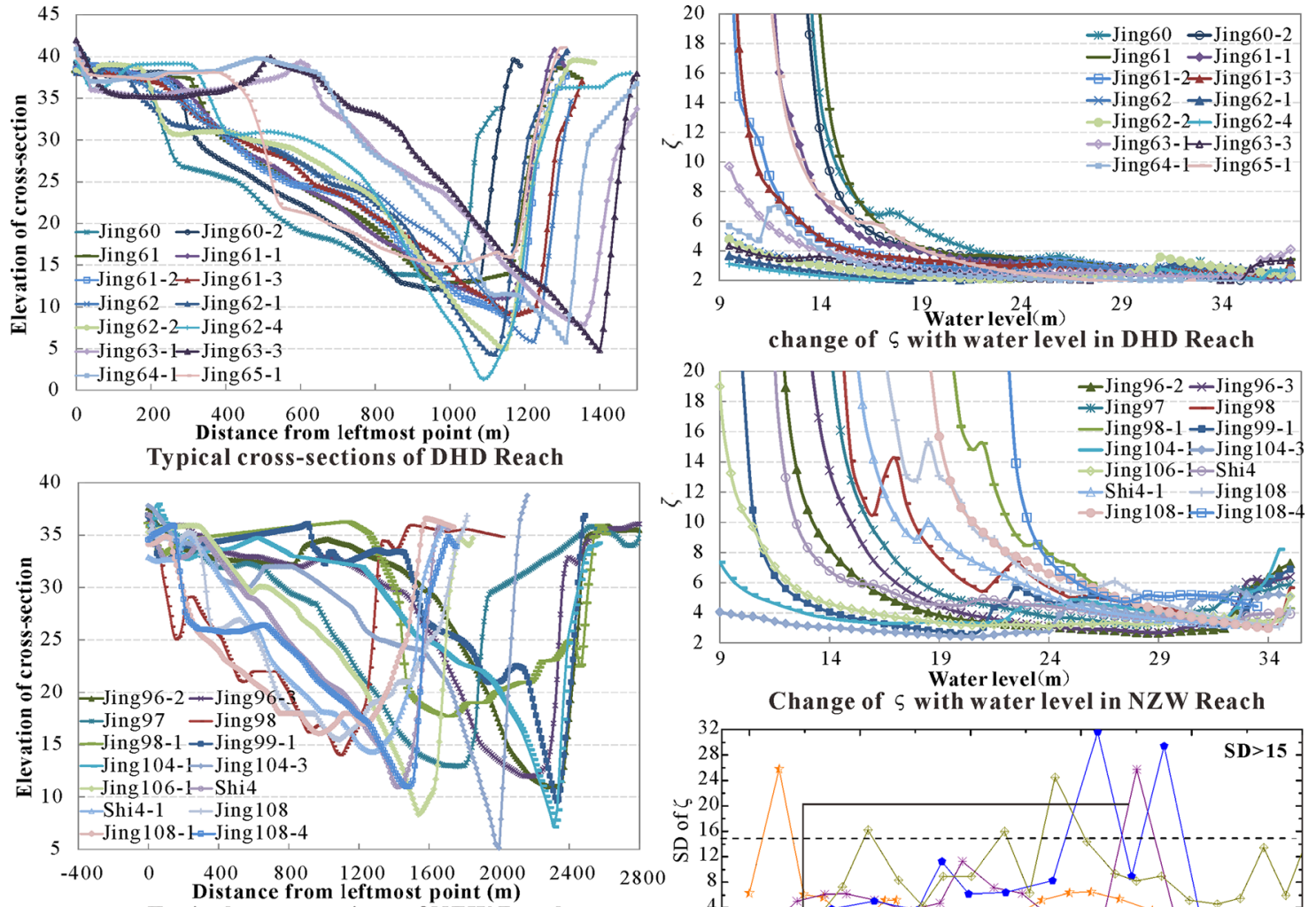

Typical cross-sections of NZW Reach
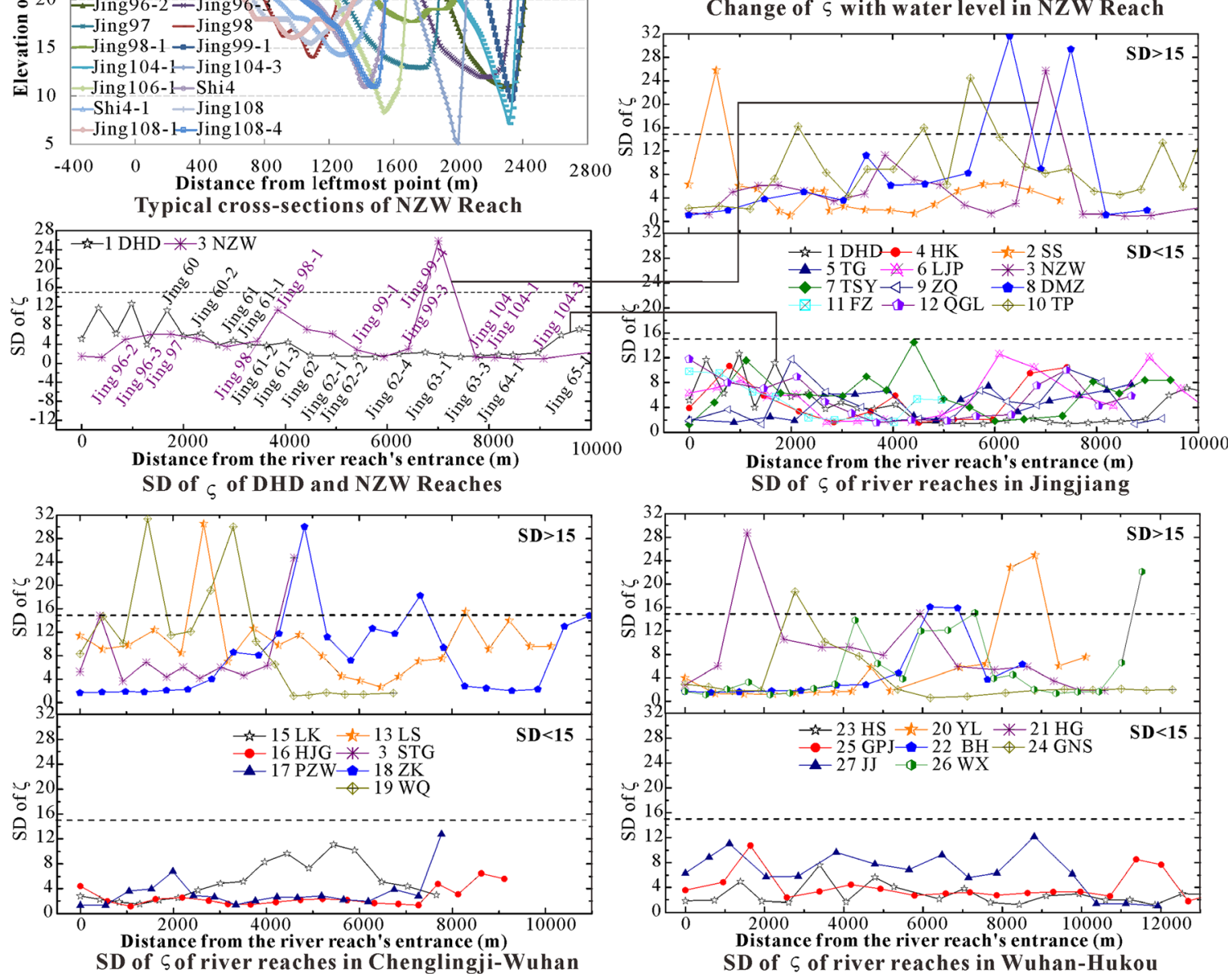

Figure 6. Cross-sectional configuration of the single-thread reach in the MLYR. Given that the narrow and deep cross-section morphology must maintain a long enough distance in order to concentrate the incoming flow from different directions, the standard deviation (referred as SD) with an mathematical expectation (4) of each cross-section at different water levels were calculated to illustrate the degree of dispersion of hydrogeometric coefficient. From figure 6 , we can see the river reaches plotted in the upper half part with SD $>15$ were non-barrier reaches, such as Nianziwan Reach; the reaches plotted in the lower half part with SD $<15$ were barrier reaches, such as Douhudi Reach. And the maximal continuous length of hydrogeometric coefficient $<4$ is $3020 \mathrm{~m}$, the minimum continuous length of hydrogeometric coefficient $<4$ in barrier river reaches is $3256 \mathrm{~m}$, thus $3200 \mathrm{~m}$ could be preliminarily considered as minimum continuous length to restrict the migration of main stream line effectively. 
hydrodynamic axis of this reach as it has barrier properties.

In the seven single-thread reaches of HankouHukou River, Reach 22 is a straight reach with no barrier properties. In the remaining six reaches with slightly bent planar morphologies, the $\zeta$ values of Reach 20, 21, 23, 25, and 27, whose cross-sections are narrow and deep, thus being beneficial for restricting hydrodynamic axis movement, are $<4$. The $\zeta$ value of Reach 26, with a wide and shallow cross-sectional configuration, is $>4$, indicating a lack of barrier properties. Node 14 and 15 are located in the upper or middle part of Reach 20 and 21 , respectively. The node deflects flow and results in an unstable hydrodynamic axis, indicating no barrier properties. Conversely, Node 19, located at the outlet of Reach 23, favours convergence rather than divergence of the upstream flow, as a result of having barrier properties.

In the seven single-thread reaches of HukouDatong River, Reach 34 is a straight reach without barrier properties. In the remaining six reaches with slightly bent planar morphologies, the $\zeta$ values of Reach 28, 29, 30, 31, and 32, whose crosssectional configurations are narrow, deep and beneficial for constraining hydrodynamic axis migrate, are all $<4$. But the $\zeta$ value of Reach 33 is $>4$, and it has no barrier properties. Node 28 and 29 are located in the middle of the right bank of Reach 30 and 31, respectively, and do not have barrier properties, whereas Node 27 and 30, located at the outlet of Reach 28 and 32, respectively, have barrier properties.

\subsection{Longitudinal profile characteristics}

According to the longitudinal gradient calculated for each reach from the measured topography data in the MLYR, by removing straight, wide, and shallow reaches, out of the remaining 17 reaches without nodes in the upper and middle part of the reach, like Reaches $1,4,5,6,7,9,11,12,15,16$, $17,23,25,27,28,29$, and 32 , only the longitudinal gradients of Reaches 12,17 , and 27 are $<1.2 \%$. As shown by the analysis above, a barrier reach usually has a greater longitudinal gradient, a sufficient driving force of water flow to prevent sedimentation, and a strong sediment carrying capacity, all of which make it beneficial for convergence, rather than divergence, of the hydrodynamic axis. Thus, a steep gradient is another characteristic of barrier river reaches.
As shown in figure 8, when the longitudinal gradient is positive, the longitudinal profile in the MLYR is basically consistent with the gradient. There are two main morphological forms prompting a steeper gradient: reaches with deeper scour holes at the outlet caused by nodes, such as Reaches 1, 7, 15, and 23, and reaches with lower thalweg points in the downstream of the concave bank because of the circulation effect of the bend, such as Reaches 5, 11, and 16. On the contrary, when erosion is located at the inlet of the reach, the gradient is usually small, such as for Reaches 8,22 , and 26 . In addition, when the reach outlet is a confluence of tributaries, the gradient $J$ is typically small because of the backwater jacking effect, such as the confluence of Dongting Lake and Poyang Lake leading to the lower slopes of Reaches 12 and 27. Continuous curves also have smaller $J$ due to the backwater jacking effect.

\subsection{Geological characteristics}

The riverbank and riverbed constitute the channel perimeter conditions, whose geological compositions and anti-scourability characteristics directly determine whether the river deformation is inclined to be narrow and deep, or wide and shallow, therefore, they play important roles on constraining movement of the hydrodynamic axis (Fotherby 2009; Habersack et al. 2016). Only when the erosional resistance of the bank is strong can it maintain a narrow and deep cross-section (El Kadi Abderrezzak et al. 2014; Bandyopadhyay et al. 2014; Langendoen et al. 2015). Julian and Torres (2006) considered the erosional resistance to be proportional to the silty clay content. As mentioned above, a barrier reach usually has greater riverbank anti-scourability. In addition, the accumulated bank protection volume is, on average, $119.0 \mathrm{~m}^{3} / \mathrm{m}$ in barrier reaches, but only $84.6 \mathrm{~m}^{3} / \mathrm{m}$ in non-barrier reaches, illustrating that even though some barrier reaches have relatively weaker riverbank compositions, their revetment volumes are greater, ensuring stronger erosion resistance. On the contrary, non-barrier reaches with poor riverbank erosion resistance cannot easily maintain stability nor effectively restrict the migration of flow dynamic axis.

Statistics show that, when the riverbed material is thinner, the bed mobility will be lower, facilitating the migration of hydrodynamic axis. As shown in figure 9 , the median diameter of bed sediment is averagely $0.185 \mathrm{~mm}$ in barrier reaches, but 

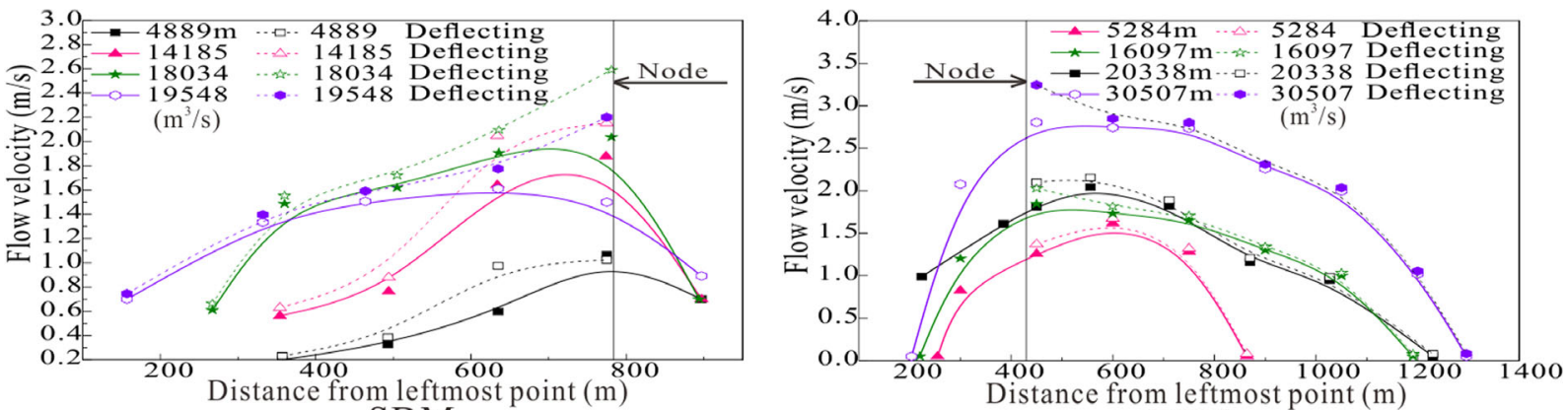

SDM

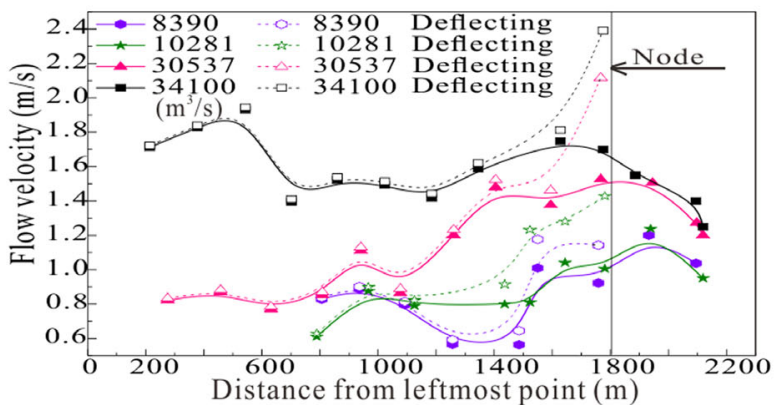

LYN

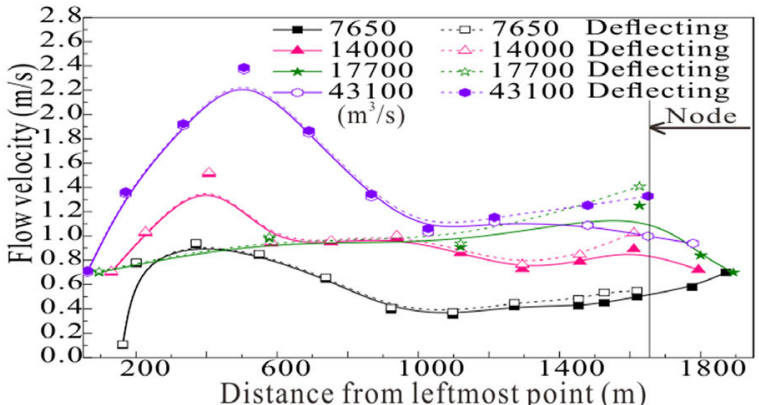

WSM
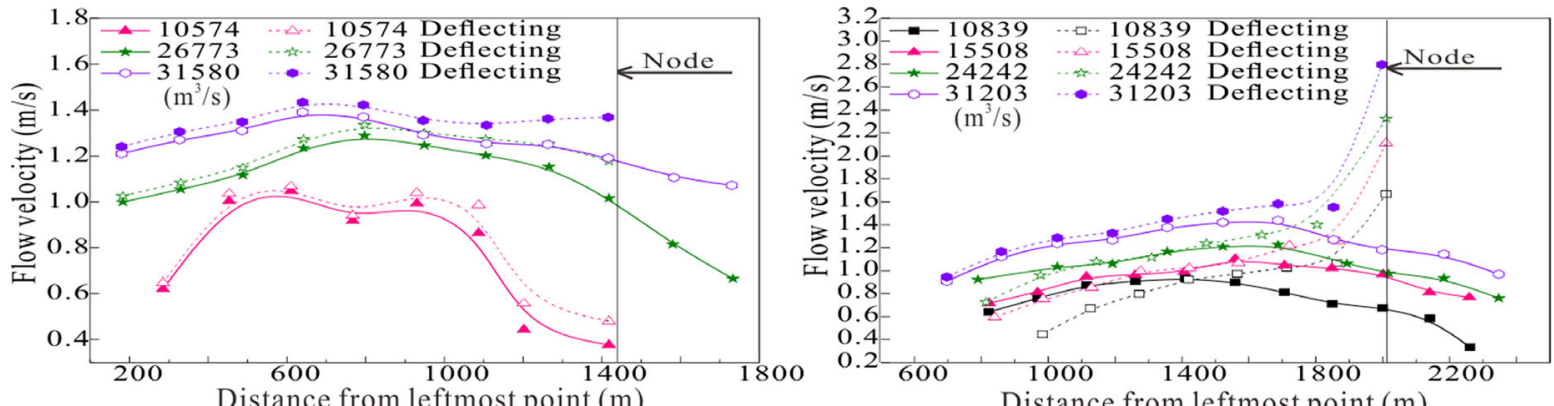

HBM

Distance from leftmost point $(\mathrm{m})$

GXM

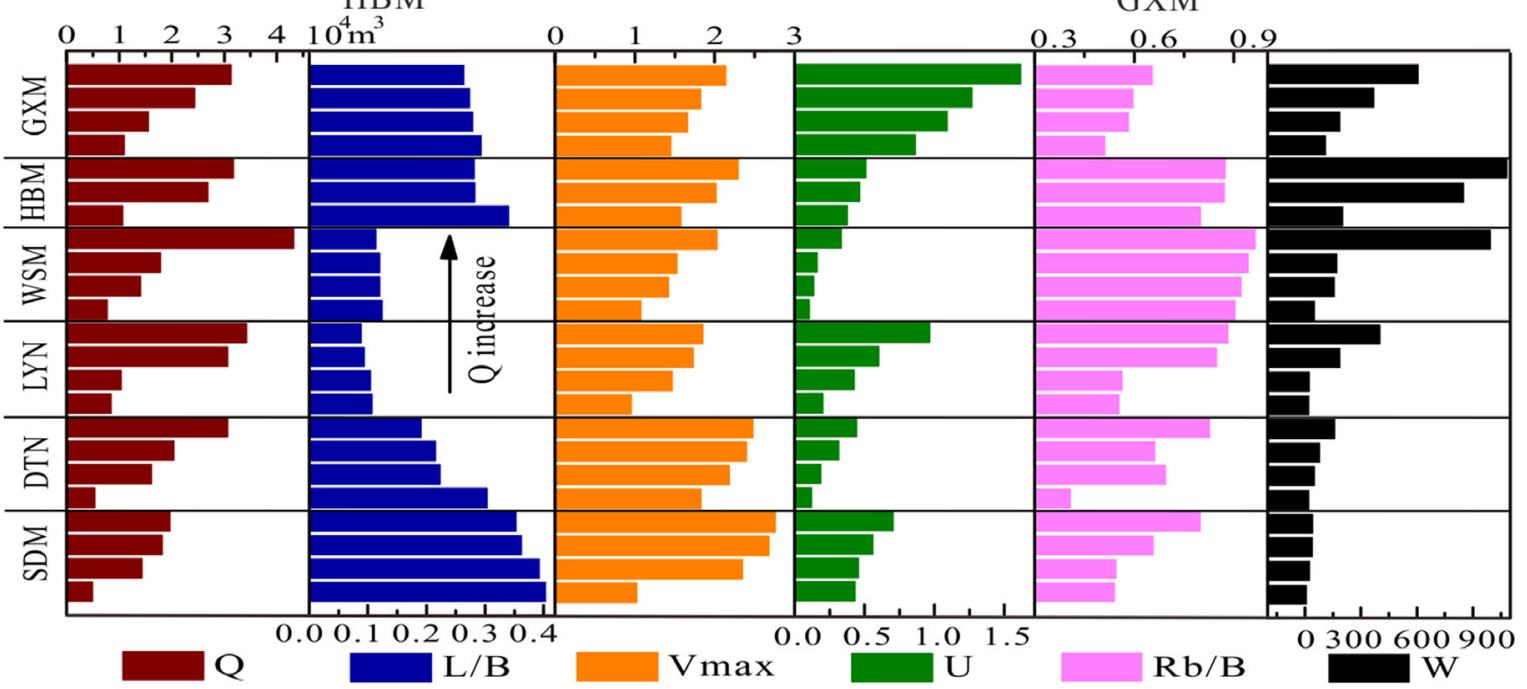

SDM:Dongyue Mountain in Shishou; DTN:Taihe Node in Damazhou; LYN:Yalan Node in Luoshan

WSM:Snake Mountain in Wuqiao; HBM:Baihu Mountain in Huguang; GXM:Xisai Mountain in Guniusha

Figure 7. Diagram of mechanism of the node deflecting flow. Refer to the boundary layer theory, the induced velocities of vortices departing from the vortex center (the leading edge of node) can be deduced, then the cross-sectional flow velocity distributions before and after the node deflecting flow can be plotted in this diagram. With the flow rate increases, the maximal circumfluence flow velocity $V_{\theta 1 \max }$ and the vortex-induced flow velocity $U$ increase, the synthetic flow velocity $V_{\theta 1}$ increases too, although the nodal length relative to the river width slightly reduces, the relative influence length of the node and the nodal deflecting flow strength enhance. 


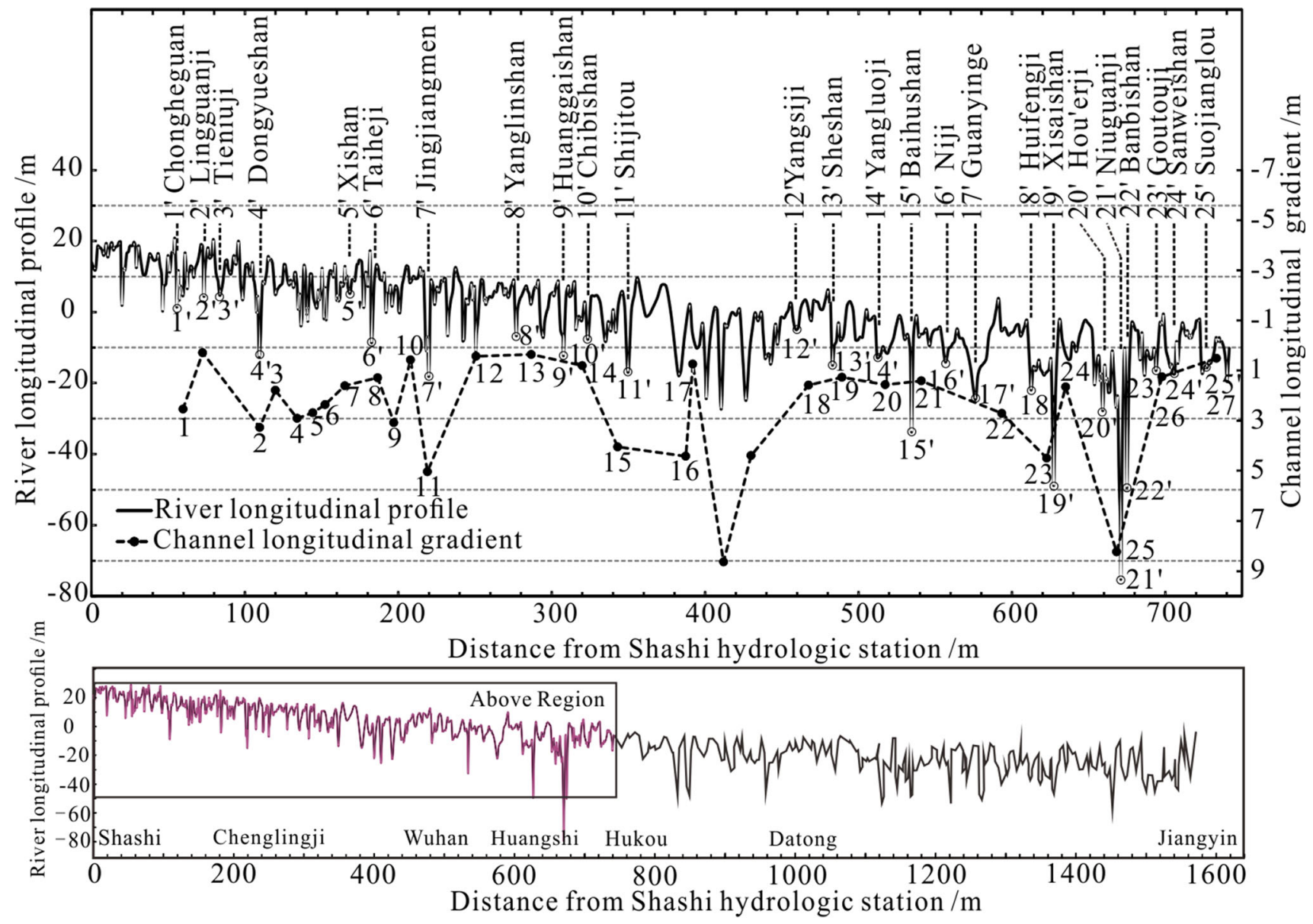

Figure 8. Longitudinal profile of the MLYR and longitudinal gradients of single-thread reaches.

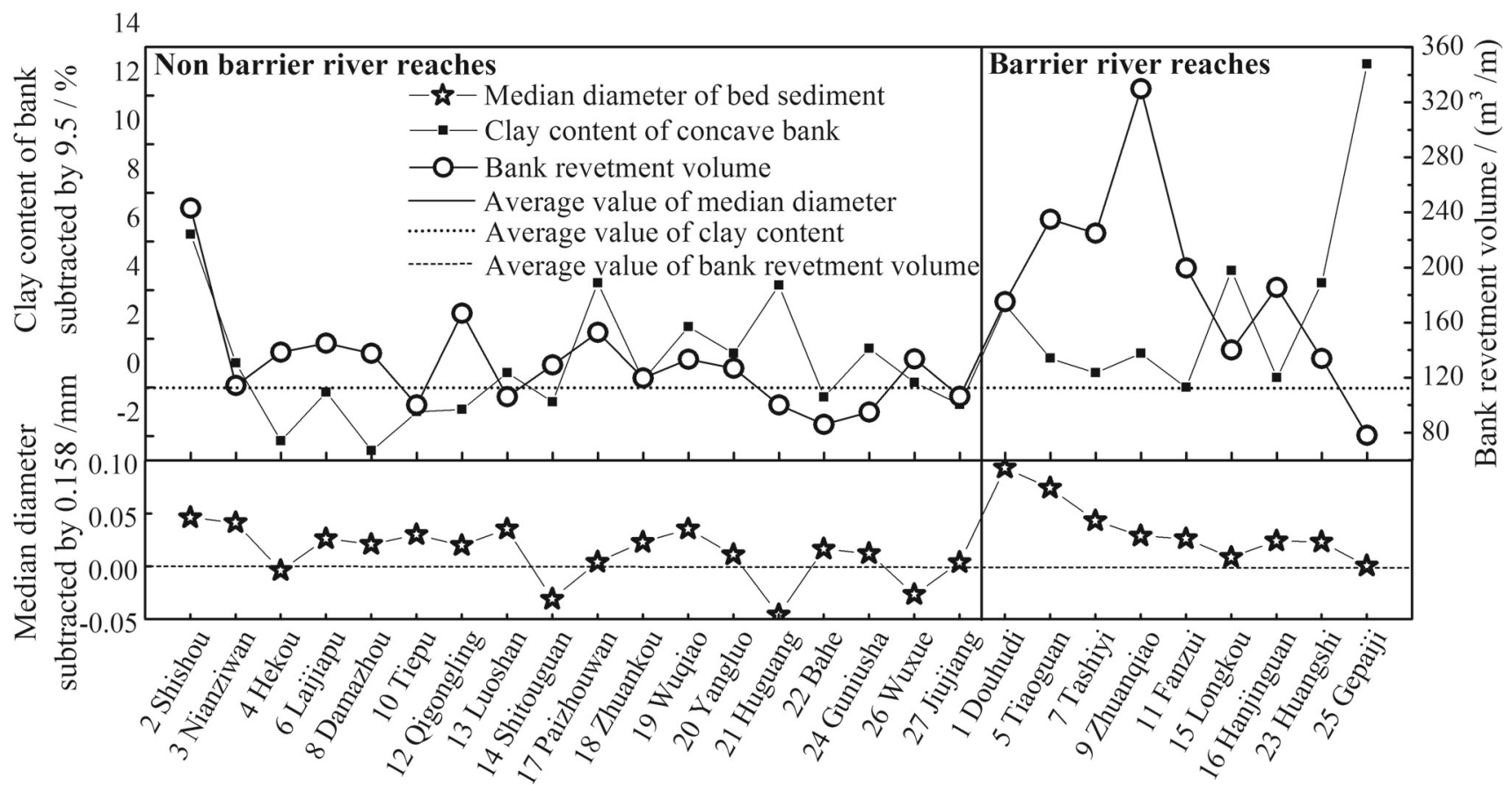

Figure 9. Riverbank silty clay content and riverbed median diameter for the single-thread reaches. 
just $0.165 \mathrm{~mm}$ in non-barrier reaches. This is resulting that barrier river reaches with coarser riverbed compositions have a greater bed resistance, whose riverbed morphology is more difficult to change, thus impeding hydrodynamic axis migration and channel adjustment, and maintaining a stable river regime. Consequently, out of the remaining 14 reaches with a slightly curved, narrow, and deep morphology, steep riverbed slopes, without flow deflecting node, only Reach 4 and 6, whose concave banks were sedimented during the period of the Lower Jingjiang River cut-off, have a silty clay content of the riverbank $>9.5 \%$, and only Reach 4 has a median diameter of bed sediment $<0.158$ $\mathrm{mm}$, indicating that the characteristics of strong erosion resistance of the riverbank and riverbed are also essential features of barrier river reaches.

\subsection{Summary}

According to the above analysis, in 34 single-thread reaches of the MLYR, Reaches 10, 13, 18, 19, 22, and 34 with straight planar morphology have no barrier properties. In addition, Reaches 3, 8, 14, 25,27 , and 34 of hydrogeometric coefficients $>4$, have no barrier properties. Reaches 2, 20, 21, 31, 32 with nodes in the upper and middle portion of the reach exhibit a deflecting flow effect, and Reaches 12, 17, and 28 have longitudinal gradients $<1.2 \%$. Finally Reaches 4 , and 6 with bank silty clay content lower than $9.5 \%$ or median diameters of bed sediment lower than $0.158 \mathrm{~mm}$, have no barrier properties, as shown in figure 10 .

Thus the function of barrier reaches is to weaken the migration amplitude of the hydrodynamic axis and centre its planimetric position after upstream channel adjustment. No matter how the upstream river regime adjusts, the original positions of the hydrodynamic axis will remain unchanged, thereby providing relatively stable inflow conditions for the lower reaches and preventing the downstream progatation of the channel adjustment.

Using the software of Mike 21 (2D water flow numerical model), the flow fields under different river regimes in the Jianli-Damazhou Reach and the Daijiazhou-Huangshi Reach were calculated, and the typical cross-sectional topography and corresponding transverse velocity distribution were extracted, as shown in figure 11. Evidently, Jianli and Daijiazhou are both braided rivers, where the flow velocity distributions are clearly diverse under different terrain and flow conditions, and translocations between the main and second branches often occur. Reach 8 having no barrier properties is located downstream of Jianli Reach, whose planimetric position of the hydrodynamic axis shows apparent migration, indicating that river adjustment of Jianli Reach impacted on the river adjustment of Reach 8. In contrast, Reach 23, located downstream of Daijiazhou Reach, a reach with barrier properties, does not appear the migration of the planimetric position of its hydrodynamic axis, even when the Daijiazhou channel adjusts drastically. Thus, it exerts no obvious effects on the evolution of its downstream reaches.

\section{Discussion}

\subsection{Planar characteristics that impede barrier properties}

The planar and cross-sectional morphology differs significantly for different river patterns. For the single-thread straight river, a small upstream perturbation would cause the separation of the hydrodynamic axis, then collapse of the concave bank with weaker anti-scourability, and the generation and gradual expansion of the scrolled bar of the opposite bank (Ghinassi et al. 2016). Until the convex point bar stabilises, the main channel matures, eventually forming a curve by the erosion and deposition of the riverbank (Song et al. 2016), indicating that it is difficult for a straight river to maintain long-term stability of the hydrodynamic axis, and only a slightly curved river with barrier properties is suitable for stabilising the hydrodynamic axis.

Reid and Brierley (2015) considered that a braided river with no constraints on either bank is the most sensitive. A braided river has two or more anabranched channels, and the hydrodynamic axis may alternate between different branches or migrate within one branch. An et al. (2013) discovered that the central bar narrowed the effective river width and resulted in a non-uniform flow velocity distribution. Furthermore, the resistance contrast relationship for each branch changed constantly, prompting translocation between different branches. This phenomenon is not uncommon (Huang et al. 2014; Clerici et al. 2015; Shi et al. 2007; Gao et al. 2013). Even in the branch interior, Sun et al. (2015) found that a relatively concentrated flow has a strong scouring force on the riverbank, leading to the lateral migration of the main stream and the scouring and silting-up of 


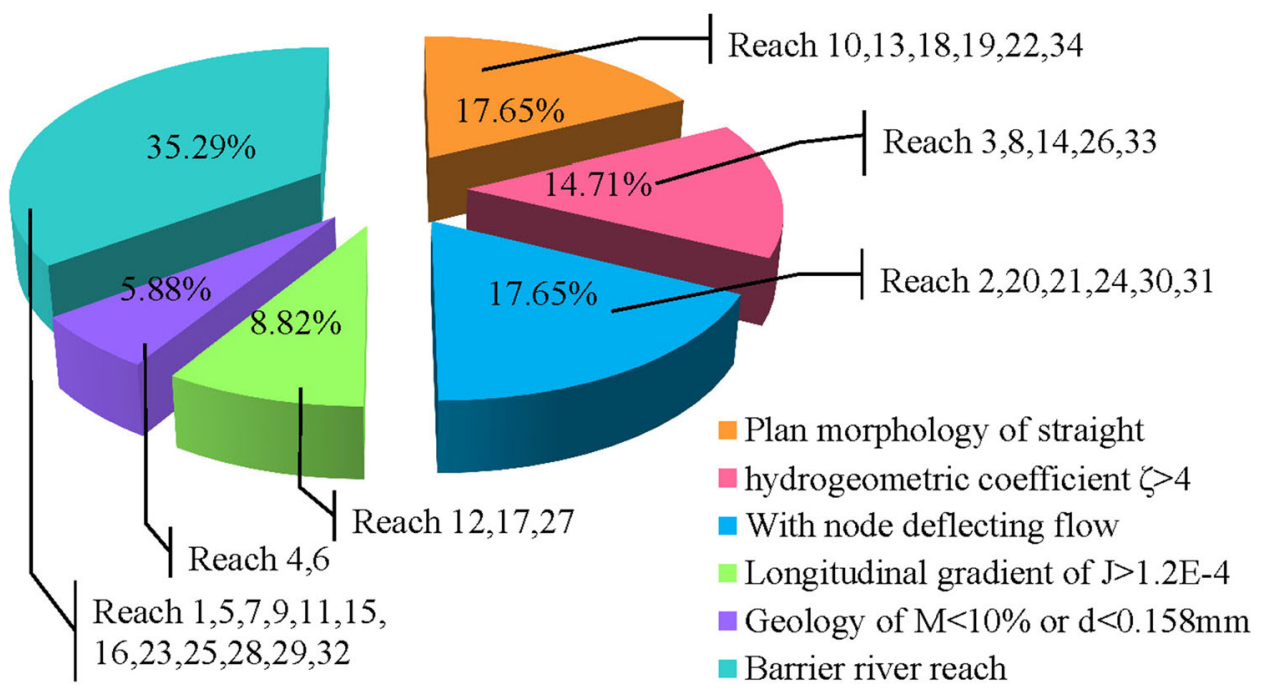

Figure 10. Barrier feature classification of 34 single thread reaches.

the sandbar. For the wandering river pattern, such as the Yellow River in China, the maximum channel migration rate was as high as $5 \mathrm{~km} / \mathrm{yr}$ (Wang et al. 2007). These types of multi-thread channels are unable to prevent long-term migration of the hydrodynamic axis, and therefore have no barrier properties.

\subsection{Cross-sectional characteristics that impede barrier properties}

River width is a key parameter influencing river evolution. A slight increase in channel width is likely to cause main stream movement, further broadening the river channel (An et al. 2013). With the $\zeta$ increase, the flow velocity decreases, the sediment carrying capacity weakens, and the possibility for movement of the hydrodynamic axis is enhanced, thus channel stability is significantly weakened (Kidová et al. 2016; Sun et al. 2015; Mossa 2016). For instance, in the lower Tongariro River in New Zealand, the upstream curve is limited by terraces on both sides and has a relatively stable river width; however, the main channel has an unrestricted floodplain downstream and often migrates (Reid and Brierley 2015).

There are many kinds of nodes in MLYR, including rock protruding from the riverbank, cement tsui, sedimentary clay layers, etc., The function mechanism of node flow deflection is similar to the spur dike (Euler and Herget 2012; Zhang et al. 2012). A node at the tail part of the reach could concentrate the incoming flow from different directions, and provide steady inflow conditions for the lower reaches; but nodes in the upper and middle parts of the reaches could cause divergence of the incoming flow directions and magnify flow deflection intensity by changing its proximity degree with the node after the upstream river has adjusted. If reasonable engineering measures are taken to eliminate the node flow deflection effect, some reaches may have barrier effect and would be beneficial to the long-term stability of the downstream river. Therefore, river regime control projects should strive to form smooth-going river curves through cutting of protruding nodes.

\subsection{Longitudinal profile or geological characteristics that impede barrier properties}

Water flow power is proportional to the riverbed longitudinal gradient (Lea and Legleiter 2016). When the gradient is steeper, the riverbed will erode and the lateral resistance accretion will make the channel narrower (Regalla et al. 2013; Kidová et al. 2016). The transport capacity of water and sediment increases, helping to reduce movement of the hydrodynamic axis and lateral migration of the main channel.

The erosion resistance of the riverbank determines the capacity of the boundary to constrain the hydrodynamic axis migration (Hajdukiewicz et al. 2016). Bank collapse may broaden the river (Sun et al. 2015) and provide substantial space for movement of the hydrodynamic axis, resulting in the loss of barrier properties. The revetment is of great significance to maintaining a stable channel (Gao et al. 2013). In the 1980s, the concave banks of Reach 5 and Reach 7 which were protected by 

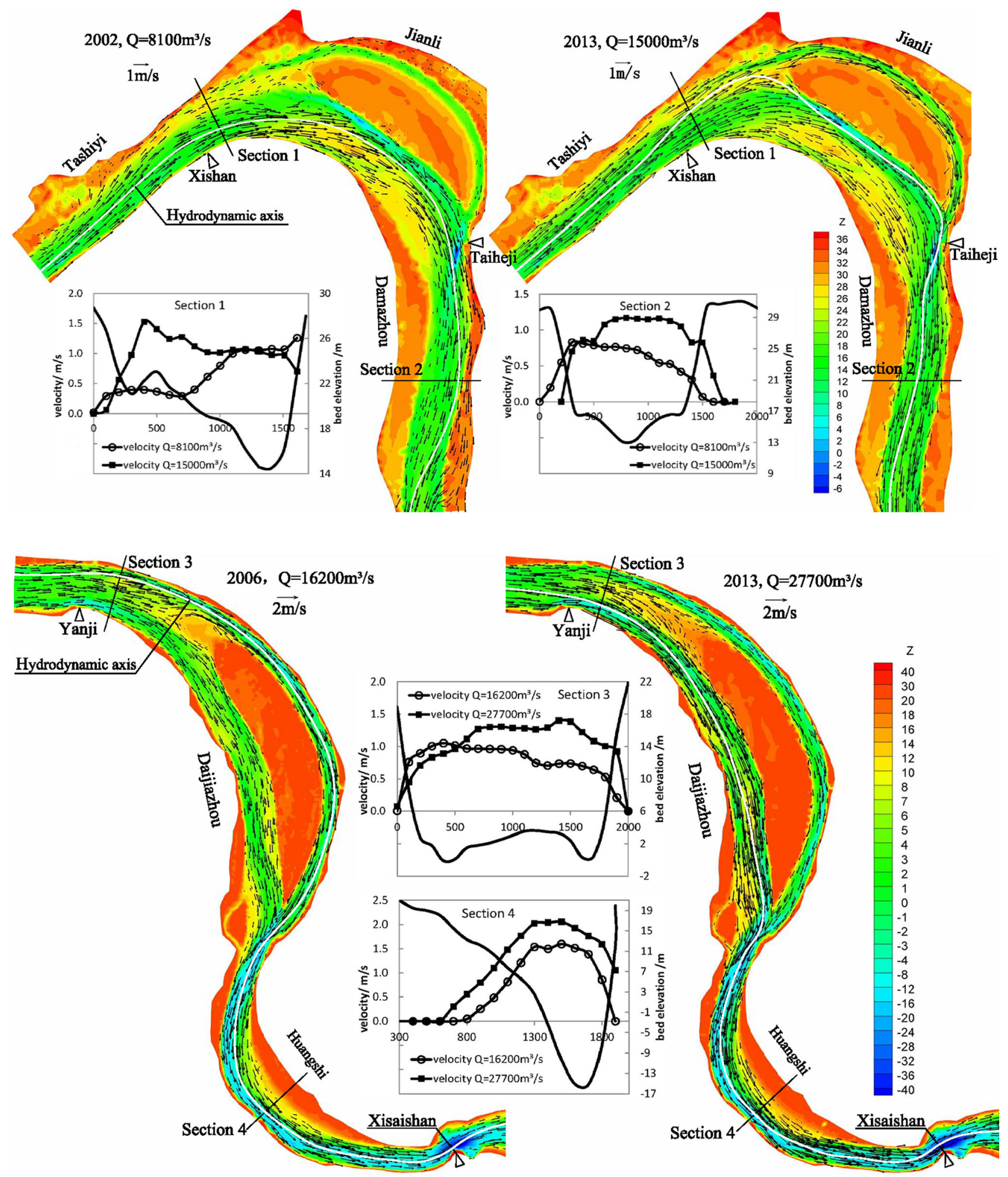

Figure 11. Typical cross-section and transverse flow velocity distribution of barrier and non-barrier reaches.

revetment had strong resistant to erosion, maintaining their narrow, deep, and slightly curved morphologies, and exerting barrier properties.

The riverbed sediment diameter has a great impact on the lateral migration of the hydrodynamic axis (Wohl 2015). The coarser the riverbed particle, the larger the lateral resistance of the hydrodynamic axis, which helps to shape a stable and narrow channel configuration (Kidová et al. 2016; Sun et al. 2015). Research shows that the coarsest median diameter is usually located at the curve dome, the head of the central bar, the 
nearshore riverbed, or the bottom of a scour hole (Zhang et al. 2012). An increasing riverbed particle size increases the sediment threshold shear stress, thereby reducing the mobility of bed sediment and being conducive to the development of a barrier river reach (Frings et al. 2014).

\section{Conclusions}

River regime adjustment has a profound influence on rivers worldwide. Taking measures to weaken or mitigate the adverse effects brought by adjustment of the river regime, as well as maintaining a stable river regime, is a constant problem for fluvial geomorphologists. This study, using the relationship of the river regime adjustment phenomena between the upstream and downstream of the MLYR, classified 34 single-thread river reaches according to their barrier properties. Twelve reaches meet all the planar, cross-sectional, longitudinal, and geological characteristics of barrier reach rivers, and therefore prevent upstream river adjustment from transferring downstream. Barrier reaches can restrict large migrations of the hydrodynamic axis after the upstream channel adjusts and help to centralise the planimetric position of the main stream, thereby providing relatively stable inflow conditions for the lower reaches. The discovery of barrier reaches enriches our previous understanding of river evolution, and provides new information for river regulation countermeasure.

For the non-barrier river reaches whose upstream and downstream river regimes are 'basically corresponding', appropriate measures should be taken to eliminate potential causes of damage, thereby creating a barrier reach effect. These measures include: timely protection of concave banks which are prone to severe collapse; taking measures to remove flow deflecting nodes in the upper and middle parts of the reaches such as protruding node cutting; narrowing the river in order to constrain floodplain development; implementing an artificial cut-off for a curve whose neck is too narrow; and carrying out riverbed roughening where the particle size of the bed sediment is too small.

For the barrier river reaches whose upstream and downstream river regimes are 'basically not corresponding', maintaining the original features of the barrier reach can prevent the loss of barrier properties due to adverse changes. Building upstream cascade reservoirs could lead to sudden changes in water and sediment conditions and may cause the large-scale collapse of concave banks and the substantial shrinkage of convex sandbars. Channels would consequently become wider and shallower and lose their original barrier properties. For instance, in the MLYR, sediment concentration decreased sharply after the impoundment of the Three Gorges Reservoir (Li et al. 2011). As a result, point bars near the convex bank in Longkou Reach were significantly eroded. The river started developing into a microbending braided river. In the long term, such changes were detrimental to maintaining the barrier properties. The timely protection of point bars in convex banks is especially important.

Finally, for the non-barrier river reaches whose upstream and downstream river regimes are "corresponding', river regulation and planning should be systematically carried out from upstream to downstream. The main aim of river regulation is to ensure a smooth relationship between the upstream and downstream river regimes, as an unsmooth relationship can prevent regulation from achieving the expected results. This is very important for main channel selection in river regulation. For instance, when the north branch of Xindi Reach was the main branch and the hydrodynamic axis was inclined to the right bank of Reach 14 that had no barrier properties, flow deflection due to Node 10 was strengthened, and the middle channel of Luxikou Reach developed, leading to scouring and the development of the direct channel of Luxikou Reach. Thus, it was appropriate to first select the main channel of Xindi Reach in the upstream and then select the main channel of Luxikou Reach. If the south branch is chosen as the main channel for Xindi Reach, the direct channel should be chosen as the main channel for Luxikou Reach.

\section{Acknowledgements}

This article was completed under the rigorous and careful guidance of Prof. Xiaofeng Zhang from Wuhan University. This study was supported by the National Natural Science Foundation of China (Grant No. 51379155) and the National Science and Technology Support Program (Grant No. 2013BAB12B02). It was also assisted by National Key Research Program of China (Grant Nos. 2016YFC0402306; 2016YFC0402310; 2016YFC0402106). Thanks to Prof. Weiguo Hou and Chunyan $\mathrm{Hu}$ from Changjiang Institute of Survey Planning Design and Research, who provided the terrain data. Thanks to Dr Yunping Yang from Key Laboratory of Engineering Sediment of Tianjin Research Institute for Water Transport 
Engineering, who provided hydrological data and helped a lot in mapping and language. Thanks to Prof. Zhaohui Weng from Hubei Provincial Water Resources Hydropower Planning Survey and Design Institute, who provided geological data.

\section{References}

An H, Chen S, Chan H and Hsu Y 2013 Dimension and frequency of bar formation in a braided river; Int. J. Sedim. Res. 28 358-367.

Armaş I, Nistoran D E G, Osaci-Costache G and Braşoveanu L 2012 Morpho-dynamic evolution patterns of Subcarpathian Prahova River (Romania); Catena 100 83-99.

Bandyopadhyay S, Ghosh K and De S K 2014 A proposed method of bank erosion vulnerability zonation and its application on the River Haora, Tripura, India; Geomorphology 224 111-121.

Bawa N, Jaina V, Shekhar S, Kumar N and Jyani V 2014 Controls on morphological variability and role of stream power distribution pattern, Yamuna River, western India; Geomorphology 227 60-72.

Bravard J-P 2010 Discontinuities in braided patterns: The River Rhône from Geneva to the Camargue delta before river training; Geomorphology 117 219-233.

Brierley G J and Fryirs K A 2005 Geomorphology and River Management: Applications of the River Styles Framework; Blackwell Publishing, Malden, 398p.

Campana D, Marchese E, Theule J I and Comiti F 2014 Channel degradation and restoration of an Alpine river and related morphological changes; Geomorphology 221 $230-241$.

Chen J, Wang Z, Li M, Wei T and Chen Z 2012 Bedform characteristics during falling flood stage and morphodynamic interpretation of the middle-lower Changjiang (Yangtze) River channel, China; Geomorphology 147$14818-26$.

Chen J-C and Ho L-C 2013 Changes in the streambank landscape and vegetation recovery on a stone revetment using the image spectrum: Case study of the Nan-Shi-Ken stream, Taiwan; Ecol. Eng. 61 482-485.

Clerici A, Perego S, Chelli A and Tellini C 2015 Morphological changes of the floodplain reach of the Taro River (northern Italy) in the last two centuries; J. Hydrol. 527 1106-1122.

Cserkész-Nagy A, Tóth T, Vajk O and Sztanó O 2010 Erosional scours and meander development in response to river engineering: Middle Tisza region, Hungary. Proc. Geol. Assoc. 121 238-247.

Dai Z and Liu J T 2013 Impacts of large dams on downstream fluvial sedimentation: An example of the Three Gorges Dam (TGD) on the Changjiang (Yangtze River); J. Hydrol. 480 10-18.

David M, Labenne A, Carozza J-M and Valette P 2016 Evolutionary trajectory of channel planforms in the middle Garonne River (Toulouse, SW France) over a 130-year period: Contribution of mixed multiple factor analysis (MFAmix); Geomorphology 258 21-39.
Doulatyari B, Basso S, Schirmer M and Botter G 2014 River flow regimes and vegetation dynamics along a river transect; Adv. Water Resour. 73 30-43.

Downs P W and Gregory K J 1993 The sensitivity of river channels in the landscape system; In: Landscape Sensitivity (eds) Thomas D S G and Allison R J, Wiley, Chichester, pp. 15-30.

Duan J G, Hea L, Fu X and Wang Q 2009 Mean flow and turbulence around experimental spur dike; Adv. Water Resour. 32 1717-1725.

El Kadi Abderrezzak K, Moran A D, Mosselman E, Bouchard J-P, Habersack H and Aelbrecht D 2014 A physical, movable-bed model for non-uniform sediment transport, fluvial erosion and bank failure in rivers; $J$. Hydro-environ. Res. 8 95-114.

Euler T and Herget J 2012 Controls on local scour and deposition induced by obstacles in fluvial environments; Catena 91 35-46.

Fang H, Han D, He G and Chen M 2012 Flood management selections for the Yangtze River midstream after the Three Gorges Project operation; J. Hydrol. 432-433 1-11.

Fotherby L M 2009 Valley confinement as a factor of braided river pattern for the Platte River; Geomorphology 103 $562-576$.

Frings R M, Döring R, Beckhausen C, Schüttrumpf H and Vollmer S 2014 Fluvial sediment budget of a modern, restrained river: The lower reach of the Rhine in Germany; Catena 122 91-102.

Fryirs K A, Brierley G J, Preston N J and Kasai M 2007 Catchment-scale (dis)connectivity in sediment flux in the upper Hunter catchment, New South Wales, Australia; Geomorphology 84 297-316.

Gao C, Chen S and Yu J 2013 River islands' change and impacting factors in the lower reaches of the Yangtze River based on remote sensing; Quat. Int. 304 13-21.

Ghinassi M, Ielpi A, Aldinucci M and Fustic M 2016 Downstream-migrating fluvial point bars in the rock record; Sedim. Geol. 334 66-96.

Goodbred Jr S L and Kuehl S A 1998 Floodplain processes in the Bengal Basin and the storage of Ganges-Brahmaputra river sediment: An accretion study using $137 \mathrm{Cs}$ and $210 \mathrm{~Pb}$ geochronology; Sedim. Geol. 121 239-258.

Greenwood M J, Booker D J, Smith B J and Winterbourn M J 2016 A hydrologically sensitive invertebrate community index for New Zealand rivers; Ecol. Indic. 61 1000-1010.

Habersack H, Hein T, Stanica A, Liska I, Mair R, Jäger E, Hauer C and Bradle C 2016 Challenges of river basin management: Current status of, and prospects for, the River Danube from a river engineering perspective; Sci. Total Environ. 543 828-845.

Hajdukiewicz H, Wyżga B, Mikuś P, Zawiejska J and Radecki-Pawlik A 2016 Impact of a large flood on mountain river habitats, channel morphology, and valley infrastructure; Geomorphology 272 55-67.

Henshaw A J, Gurnell A M, Bertoldi W and Drake N A 2013 An assessment of the degree to which Landsat TM data can support the assessment of fluvial dynamics, as revealed by changes in vegetation extent and channel position, along a large river; Geomorphology 202 74-85.

Huang M-W, Liao J-J, Pan Y-W and Cheng M-H 2014 Rapid channelization and incision into soft bedrock induced by 
human activity - Implications from the Bachang River in Taiwan; Eng. Geol. 177 10-24.

Huang C-J and Dong C-M 1999 Wave deformation and vortex generation in water waves propagating over a submerged dike; Coastal Eng. 37 123-148.

Hudson P F, Middelkoop H and Stouthamer E 2008 Flood management along the Lower Mississippi and Rhine Rivers (The Netherlands) and the continuum of geomorphic adjustment; Geomorphology 101 209-236.

Julian J P and Torres R 2006 Hydraulic erosion of cohesive river banks; Geomorphology 76 193-206.

Jun Q, Zhifeng Y and Zhenyao S 2012 Three-dimensional modeling of sediment transport in the Wuhan catchments of the Yangtze River; Procedia Environ. Sci. $132437-$ 2444 .

Karambas T V and Samaras A G 2014 Soft shore protection methods: The use of advanced numerical models in the evaluation of beach nourishment; Ocean Eng. 92129 136.

Kidová A, Lehotský M and Rusnák M 2016 Geomorphic diversity in the braided-wandering Belá River, Slovak Carpathians, as a response to flood variability and environmental changes; Geomorphology 272 137149.

Kiss T, Oroszi V G, Sipos G, Fiala K and Benyhe B 2011 Accelerated overbank accumulation after nineteenth century river regulation works: A case study on the Maros River, Hungary; Geomorphology 135 191-202.

Korpak J 2007 The influence of river training on mountain channel changes (Polish Carpathian Mountains); Geomorphology 92 166-181.

Lai X, Jiang J, Yang G and Lu X X 2014 Should the Three Gorges Dam be blamed for the extremely low water levels in the middle-lower Yangtze River? Hydrol. Process. 28 150-160.

Langendoen A M E J and Abad J D, Tassi P, Wang D, Ata R, El kadi Abderrezzak K and Hervouet J-M 2015 Improved numerical modeling of morphodynamics of rivers with steep Banks; Adv. Water Resour. 4 1-11.

Lea D M and Legleiter C J 2016 Mapping spatial patterns of stream power and channel change along a gravel-bed river in northern Yellowstone; Geomorphology 252 6679.

Li L, Lu X and Chen Z 2007 River channel change during the last 50 years in the middle Yangtze River, the Jianli reach; Geomorphology 58 185-196.

Li Q, Yu M, Lu G, Cai T, Bai X and Xia Z 2011 Impacts of the Gezhouba and Three Gorges reservoirs on the sediment regime in the Yangtze River, China; J. Hydrol. 403 $224-233$.

Mossa J 2016 The changing geomorphology of the Atchafalaya River, Louisiana: A historical perspective; Geomorphology 252 112-127.

Ramos J and Gracia J 2012 Spatial-temporal fluvial morphology analysis in the Quelite river: Its impact on communication systems; J. Hydrol. 412-413 $269-278$.
Regalla C, Kirby E, Fisher D and Bierman P 2013 Active forearc shortening in Tohoku, Japan: Constraints on fault geometry from erosion rates and fluvial longitudinal profiles; Geomorphology 195 84-98.

Reid H E and Brierley G J 2015 Assessing geomorphic sensitivity in relation to river capacity for adjustment; Geomorphology 251 108-121.

Remo J W F, Pinter N and Heine R 2009 The use of retroand scenario-modeling to assess effects of $100+$ years river of engineering and land-cover change on Middle and Lower Mississippi River flood stages; J. Hydrol. 376 403416.

Roy S and Sahu A S 2015 Quaternary tectonic control on channel morphology over sedimentary low land: A case study in the Ajay-Damodar interfluve of Eastern India; Geosci. Frontiers 6 927-946.

Shi Y, Zhang Q, Chen Z, Jiang T and Wu J 2007 Channel morphology and its impact on flood passage, the Tianjiazhen reach of the middle Yangtze River; Geomorphology 85 176-184.

Sidorchuk A 2003 Floodplain sedimentation: Inherited memories; Global Planet. Change 39 13-29.

Song X, Xu G, Bai Y and Xu D 2016 Experiments on the short-term development of sine-generated meandering rivers; J. Hydro-environ. Res. 11 42-58.

Sun J, Lin B and Yang H 2015 Development and application of a braided river model with non-uniform sediment transport; Adv. Water Resour. 81 62-74.

Surian N and Rinaldi M 2003 Morphological response to river engineering and management in alluvial channels in Italy; Geomorphology 50 307-326.

Umazano A M, Melchor R N, Bedatou E, Bellosi E S and Krause J M 2014 Fluvial response to sudden input of pyroclastic sediments during the 2008-2009 eruption of the Chaitén Volcano (Chile): The role of Logjams; J. South Am. Earth Sci. 54 140-157.

Wang Z, Wu B and Wang G 2007 Fluvial processes and morphological response in the Yellow and Weihe Rivers to closure and operation of Sanmenxia Dam; Geomorphology 91 65-79.

Williams M, Zalasiewicz J, Davies N, Mazzini I, Goiran J-P and Kane S 2014 Humans as the third evolutionary stage of biosphere engineering of rivers; Anthropocene 7 57-63.

Wohl E 2015 Particle dynamics: The continuum of bedrock to alluvial river segments; Geomorphology 241 192-208.

Zhang Q, Liu C, Xu C, Xu Y and Jiang T 2006 Observed trends of annual maximum water level and streamflow during past 130 years in the Yangtze River basin, China; J. Hydrol. 324 255-265.

Zhang H, Nakagawa H and Mizutani H 2012 Bed morphology and grain size characteristics around a spur dyke; Int. J. Sedim. Res. 27 141-157.

Zhang K, Lu Q and Yan J 2015 The lower crust conductor from Nanjing (Ning)-Wuhu (Wu) area in the middle and lower reaches of Yangtze River: Preliminary results from 3D inversion of magnetotelluric data; J. Asian Earth Sci. 101 20-29. 